\title{
Iminophosphoranylferrocenes as New Nucleophilic Organocatalysts for Regioselective Ring-opening of Epoxides
}

\author{
Nasiruzzaman Sk, Md, Vo Do Minh Hoang, and Tae-Jeong Kim \\ Department of Applied Chemistry, Kutmgpook National Lniversity, Taegu 702-701, Korea. *E-mail: tjkimaknu.ac.kr \\ Received September 12, 2009, Accepted October 6, 2009
}

Key Words: Iminophosphorany lferrocene. Organocataly st. Ring-opening. Epoxides. Regioselective

The Lewis base-catalyzed ring opening of epoxides with $\mathrm{TMSCl}$ (or $\mathrm{SiCl}_{4}$ ) has been of intense research interest. ${ }^{1-3} \mathrm{~A}$ wide variety of chiral Lewis bases such as N-oxides and phosphine oxides are proven to be highly efficient in catalyzing the formation of chlorolydrins mediated by $\mathrm{SiCl}_{4}$. In particular. $\mathrm{Fu}$ has recently established that a phosphaferrocene catalyzes the ring opening of epoxides with TMSCl , and more recently the same author reported very high yield for the enantioselective ring opening of meso-epoxides catalyzed by a series of ferrocene-fused planar-chiral N-oxides. ${ }^{1,5}$ Dermark had earlier accomplished a regioisomeric ratio up to $1: 18$ for the same reaction by employing a HMPA as a nucleophilic catalyst."

We have recently reported the serendipitous formation of 1.2-ferrocenediylazaphosphinines (1a) and l'-diphenylphosphino-1,2-ferrocenediylazaphosphinines (1b) (Chart 1), via an umisual cyclization from the reaction of glyoxal with $1-(\alpha-$ aminoethyl)-2-diphenylphosphinoferrocene (PPFA- $\mathrm{NH}_{z}$ ) and [1-( $\alpha$-aminoethyl)-1",2-bis(diphenylphosphino)]ferrocene (BPPFA-NH $\mathrm{N}_{2}$ ), respectively. ${ }^{\circ}$ These compounds constitute a new class of planar chiral ferrocenes that are of intense current research interest in the field of asymmetric cataly sis. We have further demonstrated that they are not only versatile ligands in a Cli-catalyzed cyclopropanation of styrene and $\mathrm{Pd}-\mathrm{Mo}-$ catalyzed ally lic alky lation of allyl acetates to achieve a complete diastereoselectivity but also nucleophilic catalysts for highly regioselective ring-opening of epoxides.

Intrigued by these observations, we have further investigated the preparation of ferrocene-based iminophosphoranes such as 2 (Chart 1) and demonstrated that they can serve as a new class of practical ligands for Pd-catalyzed allylic alkylation of allyl acetates ${ }^{12}$ and $\mathrm{Rh}-\mathrm{Ir}$ - catalyzed asy mmetric hydrogenation of various olefins. ${ }^{13.14}$ More recently. Ru-catalyzed asy mmetric cyclopropanation of various olefins has also been carried out successfully to achieve high diastereoselectivity (up to 95/5 $d r$ in favor of the cis-isomer). ${ }^{15}$ One may anticipate that 2 should

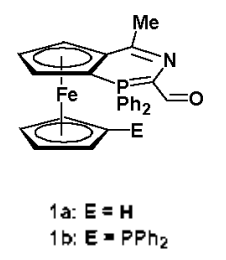

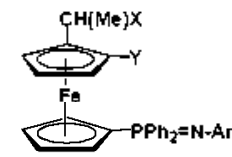

$\mathrm{Ar}=2,6-\mathrm{Me}_{2}-\mathrm{C}_{6} \mathrm{H}_{3}$

2b: $X=N M q_{2}, Y=P h_{2}=\mathrm{N}-\mathrm{Ar}$

2द: $X=O M e, Y=P P h_{2}=\mathrm{N}-A \mathrm{Ar}$

Chart 1 act as tightly binding chelates and thus would be capable of stabilizing metal centers involved in catalytic cycles. even in rather low oxidation states. ${ }^{16.17}$ Furthernore. very ligh stereoselectivity observed with 2 in the reactions cited above may be somehow related with the presence of the sterically demanding iminophosphoranes.

It is thus strongly recommended to design and synthesize 1.2-ferrocenediylazaphosphinines substituted by iminophosphoranes such as 3 for use as a ligand or a nucleopluilic cataly st in various organic transformations. As the first step to benchmark the potentiality of 3 , we wish to report their synthesis and application as nucleopluilic catalysts to the ring-opening of a series of epoxides with TMSCl. We have reasoned that our compounds 2 and 3, carrying in principle donor sites of $s p^{2}$-nitrogen and one carbonyl oxygen (3). would put an entry into a new family of nucleophilic catalysts.

\section{Results and Discussion}

Synthesis and characterization. Scheme 1 shows the preparative method leading to the formation of a series of 1 '-iminophosphoranyl-1,2-ferrocenediylazaphospluinines (3a-c). The method requires initially the reaction of $[1-(\alpha-a m i n o e t h y l)$ 2-(diphenylphosphino)] ferrocene (PPFA- $\mathrm{NH}_{2}$ ) with glyoxal to form via heterocyclization 1.2-ferrocenediylazaphosplinine (1a). Simple extension of the same method by replacing PPFA-

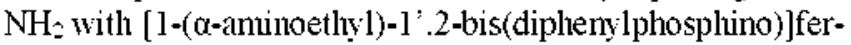
rocene (BPPFA- $\mathrm{NH}_{2}$ ) led to the formation of a phosphine analogue, 1'-diphenylphosphino-1,2-ferrocenediylazaphosphinine (1b) ${ }^{8}$ Subsequent entoloyment of the conventional Staudinger reaction that involves the reaction of $\mathbf{1 b}$ with arylazides led eventually to the formation of their ininophosphorane analogues of 1.2-ferrocenediylazaphosphinines (3a-c).

Catalysis. In an effort to benchmark the potential of our compounds $2 a-c$ and 3 a-c as Lewis base catalysts. we also per-

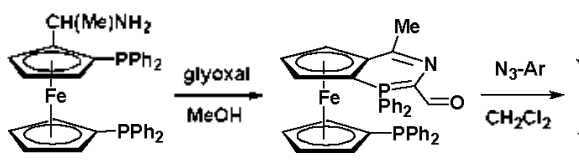

(1b)

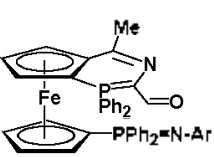

3a: $\mathrm{Ar}=\mathrm{C}_{\mathrm{\theta}} \mathrm{H}_{5}$ 3b: $\mathrm{Ar}_{\mathrm{r}}=2,6-\mathrm{Me}_{2}-\mathrm{C}_{\mathrm{B}} \mathrm{H}_{3}$ 3c: $\mathrm{Ar}=2,6-\mathrm{Pr}_{2}-\mathrm{C}_{\mathrm{B}} \mathrm{H}_{3}$
Scheme 1 
Table 1. Regioselective Ring-Opening of Epoxides with TMSCl Catalyzed by 2 and 3

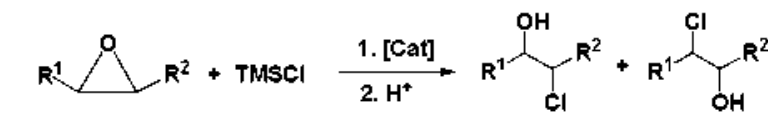

(A)

(B)

\begin{tabular}{|c|c|c|c|c|c|}
\hline Entry & Eposide & Catalyst & Tine (li) & Yield $(\%)^{a}$ & $\mathrm{~A}: \mathrm{B}^{b}$ \\
\hline 1 & & $2 a$ & 1 & 99 & - \\
\hline 2 & & $2 b$ & 1 & 99 & - \\
\hline 3 & & $2 c$ & 1 & 99 & - \\
\hline 4 & & 3a & 0.25 & 99 & - \\
\hline 5 & & $3 b$ & 0.25 & 99 & - \\
\hline 6 & & $3 c$ & 0.25 & 99 & - \\
\hline 7 & & $2 a$ & 2 & 99 & $9: 90$ \\
\hline 8 & & $2 b$ & 2 & 98 & $2: 98$ \\
\hline 9 & & $2 c$ & 2 & 98 & $5: 95$ \\
\hline 10 & & 3a & 2 & 99 & $3: 97$ \\
\hline 11 & & $3 b$ & 2 & 99 & $8: 92$ \\
\hline 12 & & $3 c$ & 2 & 99 & $4: 96$ \\
\hline 13 & & $2 a$ & 2 & 99 & $94: 6$ \\
\hline 14 & & $2 b$ & 2 & 98 & $63: 37$ \\
\hline 15 & & $2 c$ & 2 & 98 & $87: 13$ \\
\hline 16 & & $3 a$ & 2 & 99 & $100: 0$ \\
\hline 17 & & $3 b$ & 2 & 98 & $100: 0$ \\
\hline 18 & & $3 c$ & 2 & 99 & 1000 \\
\hline 19 & & $2 a$ & 2 & 99 & $100: 0$ \\
\hline 20 & & $2 b$ & 2 & 99 & $25: 75$ \\
\hline 21 & & $2 c$ & 2 & 98 & $100: 0$ \\
\hline 22 & & $3 a$ & 2 & 99 & $100: 0$ \\
\hline 23 & & $3 b$ & 2 & 99 & $100: 0$ \\
\hline 24 & & $3 c$ & 2 & 99 & $100: 0$ \\
\hline 25 & & $2 a$ & 2 & 99 & $82: 18$ \\
\hline 26 & & $2 b$ & 2 & 99 & $73: 27$ \\
\hline 27 & & $2 c$ & 2 & 99 & $81: 19$ \\
\hline 28 & & $3 a$ & 2 & 99 & $94: 6$ \\
\hline 29 & & $3 b$ & 2 & 99 & $91: 9$ \\
\hline 30 & & $3 c$ & 2 & 99 & $93: 7$ \\
\hline 31 & & $2 a$ & 2 & 99 & $99: 1$ \\
\hline 32 & & $2 b$ & 2 & 98 & $99: 1$ \\
\hline 33 & & $2 c$ & 2 & 98 & $99: 1$ \\
\hline 34 & & $3 \mathbf{a}$ & 2 & 99 & $100: 0$ \\
\hline 35 & & $3 b$ & 2 & 99 & $100: 0$ \\
\hline 36 & & $3 c$ & 2 & 99 & $100: 0$ \\
\hline
\end{tabular}

"Determined by GC. ${ }^{k}$ Determined by GC.

formed the catalytic ring opening of some epoxides with TMSCl. Typical experimental procedure involves treatment of an epoxide with 1.2 equiv of $\mathrm{TMSCl}$ and $5 \mathrm{~mol} \%$ of 2 or 3 in $\mathrm{CH}_{2}$ $\mathrm{Cl}_{2}$ at room temperature. followed by deprotection of the resulting TMS ether with acid to afford cleanly a chlorohy'drin as a product. The results are illustrated in Table 1 .

The table shows that regardless of the types of catalysts. all reactions, except cyclohesene oxide. go to completion within $2 \mathrm{~h}$ with inversion of configuration at the carbon undergoing substitution as verified by comparison with the known chlorohydrins. The reactivity of 3 both in terms of reaction time and the chemical yield compares well with that of $1 \mathrm{a}$ or $1 \mathbf{b}$ in spite of the presence of sterically demanding iminophosphoranes. Yet. no ring opening is observed in the absence of the cataly'sts under otherwise identical conditions.

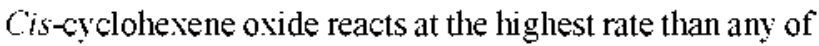
the substrates employed (runs 1-6). Slower reaction rates with other unsymmetrical epoxides carrying bulkier functional groups may be explained in terms of hindered approach to the TMSnucleoplile intermediate. The regioselectivity in the reaction of these unsymmetrical epoxides is governed by both steric and electronic effects. This is illustrated in the high level but opposite sense of regioselectivity in the opening of styrene oxide (runs 7-12) and other terminal epoxides (runs 13-36). For example, in the case of alkene oxides $\left(\mathrm{R}^{1}=\mathrm{CH}_{2} \mathrm{Cl}, \mathrm{Bu}\right.$. $\left.\mathrm{CH}_{2} \mathrm{OPh}\right)$ and 2-methyl styrene oxide $\left(\mathrm{R}^{1}=\mathrm{Ph} \mathrm{R}^{2}=\mathrm{Me}\right)$. displacement occurs preferentially at the less lindered carbon (runs 13-36), barring an overriding electronic effect observed with styrene oxide (runs 7-12). It is worth noting that parallel observations have already been made by us and others. However. little effect on the regioselectivity is observed by a stuctural change in the catalyst. In fact, in some cases, introduction of the sterically demanding iminophosporane as in $\mathbf{2}$ or $\mathbf{3}$ even enhances not only catalytic performance but also regioselectivity when compared with 1a or $\mathbf{1 b}$.

Although detailed mechanistic studies have yet to be carried out, our working hypothesis for the catalytic cycle may be the same as that proposed by others. ${ }^{6}$ As such the first step in the catalytic cycle is expected to be the formation of a cationic complex I or II and III or IV between TMSCl and 2 or $\mathbf{3}$ (Chart 2). Donor-stabilized silyl cations are ubiquitous, and the structure and reactivity of resulting pentacoordinate silicon compounds are now well documented. ${ }^{18}$ The presence of the neighboring phosphoranylinine may provide a better platform for the stabilization of the silyl complex, leading to higher efficiency: Subsequent complexation of the epoxide to the silicon cation followed by nucleophilic attack with the chloride ion in an $\mathrm{S}_{\mathrm{N}} 2$ fashion will eventually lead to ring-opening.

\section{Expenimental Section}

Materials and methods. All manipulations were carried out under an atmosphere of nitrogen using Schlenk techniques. Solvents were purified by standard methods and were freshly distilled prior to use. All conmercial reagents were used as received unless otherwise stated. ${ }^{1} \mathrm{H}$ and ${ }^{31} \mathrm{P} N \mathrm{NM}$ spectra were recorded on a Varian Unity Plus spectrometer operating at 300 and $121.5 \mathrm{MHz}$, respectively: ${ }^{1} \mathrm{H}$ shifts are reported relative to internal TMS and ${ }^{31} \mathrm{P}$ shifts relative to $85 \% \mathrm{H}_{3} \mathrm{PO}_{4}$. Coupling constants are in $\mathrm{Hz}$. Mass spectra were obtained with Micromass QUATTRA II GC8000 series model with electron energy of 20 or $70 \mathrm{eV}$. Microanalyses were performed by the Center for Instrumental Analy sis. KNU. GC-Mass spectra were obtained by using a Micromass high resolution Quatro II GC8000 series model with an electronic energy of $20 \mathrm{or} 70 \mathrm{eV}$. Starting compounds and BPPFA- $\mathrm{NH}_{2}$ were prepared according to the literature methods. 


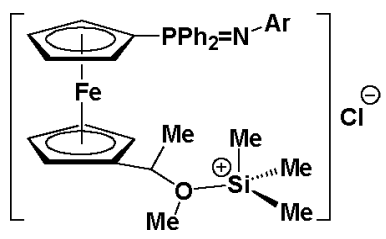

(I)

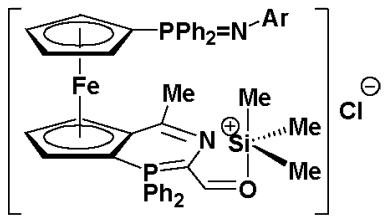

(III)

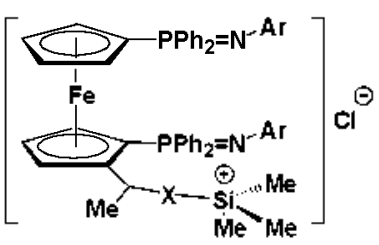

(II)

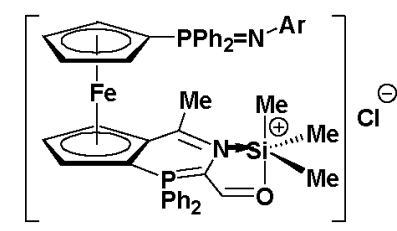

(IV)
Chart 2

Synthesis of 3a. To a solution of $1 \mathbf{b}(0.50 \mathrm{~g} .0 .78 \mathrm{mmol})$ in dichloromethane $(20 \mathrm{~mL})$ was added drop wise an equimolar amount of azidobenzene $(0.090 \mathrm{~g} .0 .78 \mathrm{mmol})$ under an inert atmosphere. After stirring for $t h$ at RT. the solvent was removed under vacuum and the remaining solid washed with ether ( 20 $\mathrm{mL}$ ). The solid was taken up in a small amount of dichloromethane for chromatographic separation on silica gel. A single orange band was eluted with mixture of hexane and ethyl acetate $(8: 2)$ to give orange solids after removal of solvents. Recrystallization from a mixture of dichloromethane and hexane (1:4) yielded $0.17 \mathrm{~g}$ of $3 \mathrm{a}(29.8 \%)$. ${ }^{\mathrm{H}} \mathrm{H} \mathrm{NMR}\left(\mathrm{CDCl}_{3}\right) \hat{0} 9.56$ (d. $J=25,1 \mathrm{H}, \mathrm{CHO}), 7.75-7.20\left(\mathrm{~m}, 20 \mathrm{H}, \mathrm{PPh}_{-} \&=\mathrm{PPh}_{-}\right) .7 .18-$ $6.82\left(\mathrm{~m} .5 \mathrm{H}, \mathrm{N}-\mathrm{C}_{6} \mathrm{H}_{5}\right) .4 .77-4.34\left(\mathrm{~m} .3 \mathrm{H} . \mathrm{C}_{5} \mathrm{H}_{3}\right) .4 .10 / 3.40(\mathrm{br}$ 4H. $\left.\mathrm{C}_{3} \mathrm{H}_{4}\right) .2 .21\left(5.3 \mathrm{H}, \mathrm{CH}_{3}\right) .{ }^{31} \mathrm{P} \mathrm{NMR}\left(\mathrm{CDCl}_{3}\right)$ o $0.44(\mathrm{~s}),-5.71$ (s). HRMS: $727.3396\left[\mathrm{M}^{-}+\mathrm{H}\right]$. Anal. Calc. for $\mathrm{C}_{44} \mathrm{H}_{36} \mathrm{~N}_{2} \mathrm{OP}_{2}$ Fe: C, 72.74: H. 4.99: N. 3.86. Found: C. 72.06: H. 4.56: N. 3.66 .

Synthesis of $3 \mathbf{b}$. The title compound was prepared in the same manner as described above for 3 a by simply replacing azidobenzene with azido-2,6-dimethylbenzene. The product was obtained as a brown solid. Yield: $25 \% .{ }^{1} \mathrm{H} \mathrm{NMR}\left(\mathrm{CDCl}_{3}\right)$ ò $9.5+(\mathrm{d} J=25 . \mathrm{IH} . \mathrm{CHO}) .7 .75-7.20\left(\mathrm{~m} .20 \mathrm{H}, \mathrm{PPh}_{\mathbf{\alpha}}=\mathrm{PPh}_{\mathbf{\Sigma}}\right)$, $6.88-6.62\left(\mathrm{~m}, 3 \mathrm{H}, \mathrm{N}-\mathrm{C}_{6} \mathrm{H}_{3}\right), 4.77-4.34\left(\mathrm{~m}, 3 \mathrm{H}, \mathrm{C}_{5} \mathrm{H}_{3}\right)+.10 / 3.40$ (br. + H. C $\mathrm{H}_{4}$ ), 2.21 (s. $\left.3 \mathrm{H} . \mathrm{CH}_{3}\right) .1 .97\left(\mathrm{~s}, 6 \mathrm{H}, \mathrm{CH}_{3}-\mathrm{C}_{6} \mathrm{H}_{3}\right){ }^{31} \mathrm{P}$ $\mathrm{NMR}\left(\mathrm{CDCl}_{3}\right) \dot{\delta}-5.67$ (s). $-8.86(\mathrm{~s})$. HRMS: $755.0282\left[\mathrm{M}^{-}+\right.$ $\mathrm{H}$ ]. Anal. Calc. for $\mathrm{C}_{46} \mathrm{H}_{4,} \mathrm{~N}_{2} \mathrm{OP} \mathrm{P}_{2} \mathrm{Fe}: \mathrm{C}, 73.22: \mathrm{H} .5 .34 ; \mathrm{N}, 3.71$. Found: C. 72.96: H. 5.23: N, 3.66.

Synthesis of $3 c$. The title compound was prepared in the same manner as described above for 3 a by simply replacing azidobenzene with azido-2,6-diisopropylbenzene. The product was obtained as a brown solid. Yield: $21 \% .{ }^{1} \mathrm{H} \mathrm{NMR}\left(\mathrm{CDCl}_{3}\right)$ ò 9.54 (d. $J=25, \mathrm{lH}, \mathrm{CHO}), 7.75-7.20$ (m. $20 \mathrm{H}, \mathrm{PPh}_{2} \&=\mathrm{PPh}_{2}$ ), $6.93-6.76\left(\mathrm{~m} .3 \mathrm{H}, \mathrm{N}-\mathrm{C}_{6} \mathrm{H}_{3}\right), 4.73-4.3+\left(3 \mathrm{H} . \mathrm{C}_{3} \mathrm{H}_{3}\right), 4.40 / 3.40$ (br. $\left.+\mathrm{H}, \mathrm{C}_{:} \mathrm{H}_{4}\right), 3.30$ (sept $J=6.6,2 \mathrm{H}, \mathrm{CHMe}$ ). $2.2 \mathrm{l}$ (s. $3 \mathrm{H}$. $\left.\mathrm{CH}_{3}\right), 0.95\left(\mathrm{~d} J=6.9 .6 \mathrm{H} . \mathrm{CH} / e_{2}\right), 0.84\left(\mathrm{~d} J=6.9 .6 \mathrm{H} . \mathrm{CHM} e_{2}\right)$. ${ }^{31}$ PNMR $\left(\mathrm{CDCl}_{3}\right) \delta-5.64(\mathrm{~s}),-9.72(\mathrm{~s})$. HRMS: $811.1200\left[\mathrm{M}^{-}+\right.$ $\mathrm{H}]$. Anal. Calc. for $\mathrm{C}_{510} \mathrm{H}_{48} \mathrm{~N}_{2} \mathrm{OP}_{2} \mathrm{Fe}$ : C. 74.07: H. 5.97: N. 3.46 . Found: C, 73.87; H. 5.46; N, 2.95.

General procedure for the ring-opening reaction. Representative procedure for Table 1, including monitoring the background reaction: a solution was prepared of hex-1-ene oxide
(0.148 $\mathrm{g}, 1.48 \mathrm{mumol})$ and TMSCl $(0.230 \mathrm{~nL} .1 .81 \mathrm{mmol})$ in $\mathrm{CH}_{2} \mathrm{Cl}_{2}(4.52 \mathrm{~mL})$ in a Scllenk tube. After degassing the solution by the freeze-and-thaw method three times. a portion of this stock solution was transferred to a $5 \mathrm{~mL}$ screw-capped vial (background reaction). and $1.69 \mathrm{~mL}$ of the stock solution $(0.49 \mathrm{mmol}$ of epoxide, $0.60 \mathrm{mmol}$ of TMSCl) was transferred to a Schlenk tube containing cataly st $3(0.025 \mathrm{mmol})$. The two reactions were allowed to proceed at room temperature and monitored by GC equipped with CBP-20 on a Shimadzu GC17A. After $15 \mathrm{~min}$, the catalyzed reaction was complete and the background reaction had not proceeded ( $<5 \%$ conversion). For the catalyzed reaction, the solvent was removed in vacuo. and the TMS ether was treated with $\mathrm{HCl}\left(1 \mathrm{M}\right.$ in $\left.\mathrm{Et}_{2} \mathrm{O}\right)$ for $1 \mathrm{~h}$ at room temperature. The resulting cllorohydrins were purified by flash chromatography on silica gel (hexane:ethylacetate $8: 2$ ). and their NMR identifications were made by conparison with literature data.

\section{Conclusion}

In sunumary. we put into entry ininophoranyl-1.1 '-bis(diphenylphosphino)-2-[(dimethy lamino)ethyl]ferrocene (2a-c) and 1'-iminophosphoranyl-1.2-ferrocenediylazaphosphinines (3a-c) as a new class of Lewis base cataly'sts for ring-opening of some epoxides. Their catalytic performances in terms of both reactivity and regioselectivity conpares well with not only their parent 1.2-ferrocenediylazaphosphinines (1a \& 1b) but also welldocumented catalysts such as phosphaferrocene and HMPA. although asymmetric version of this reaction has yet to be carried out.

Acknowledgments. This work was supported by the Ministry for Health. Welfare \& Fanily Affairs through the Korea Healthcare Technology R\&D Project (grant No.A090193). Spectral measurements were performed by the KBSI.

\section{Refeiences}

1. Erden, I. In Compwhensive Heterockic Chentistry, 2nd ed; Padwa, A., Ed.: Pergamon Press: Oxford, 1996: Vol. 1A. Chapter 1.03. (b) Bartok, M.; Lang, K. L. In The Chentistry of Heterocyclic Conpounds; Weissberger, A.; Taylor, E. C., Eds.; Wiley: New York, 1985; Vol. 42, Part 3, p. 1. (c) Rao, A. S.; Paknikar, S. K.; Kirtane, J. G. Tetrahedron 1983, 39, 2323. (d) Denmark, S. E:; Barsanti, P. A.; Beutner, G. L.; Wilson, T. W. Adw: Sinth. Catal. $2007,349,567$

2. (a) Tohnson, R. A.; Sharpless, K. B. In Compwhensive Orgonic Synthesis, Vol. 7, Oxidation: Ley, S. V., Ed.; Pergamon Press: Oxford, 1991: Chapter 3.2. (b) Johnson, R. A.: Sharpless, K. B. In Catalvic Astmmetric Synthesis; Ojima, I., Ed.; VCH: Weinheim, 1993; Chapter 4.1. (c) Tacobsen, E. N. In Catalyric Astmmetric Synthesis: Ojima, I., Ed.: VCH: Weinheim, 1993: Chapter 4.2.

3. For leading references of enantioselective ring opening of epoxides, see: (a) Nugent, W. A. J.Ant Chent. Soc: 1992, 114, 2768. (b) Martinez, L. E.: Leighton, I. L.: Carsten, D. H.; Jacobsen, E.N.J.Am Chem Soc. 1995, 117, 5897. (c) Tohunaga, M. Larrow, J. F.; Kakiuchi, F; Jacobsen, E. N. Science 1997, 277, 936. (d) Cole, B. M.; Shimizu, K. D; Krueger, C. A.; Harrity, J. P. A.; Snapper, M. L.: Hoveyda A. H. Angew Chem., Int Ed Engl 1996. 35, 1668 . (e) Hodgson, D. M.: Gibbs, A. R.: Lee, G. P. Tetrahedron 
1996, 52, 14361. (f) Matsunaga, S.: Das, J.: Roels, J.; Vogl, E. M.: Yamannoto, N.: Iida, T.: Yamaguchi, K.: Shibasaki, M. $J$. Am. Chem. Soc. 2000, 122, 2252 .

4. Garrett, C. E.; Fu, G. C. J. Org. Chem. 1997,62,4534.

5. Tao, B. Lo, M.-C. Fu, G. C. J. Am. Chent. Soc. 2001, 123, 353.

6. Dennark, S. E.; Barsanti, P. A.; Wong, K.-T.: Stavenger, R. A. J. Org. Chem. 1998, 63,2428.

7. Hwang, G.-H.; Ryu, E.-S.; Park, D.-K: Shim, S. C.; Cho, C. S.; Kim, T.-J.; Teong, I. H.; Cheong, M. Organometallics 2001, 20 , 5784.

8. Paek, S. H.: Co, T. T.: Lee, D. H.; Park, Y. C.: Kim, T.-J. Bull. Korean Chem. Soc. 2002, 23, 1702

9. For recent reviews on planar chiral terrocenes, see: (a) Richards, C. J.: Locke, A. I.; Tetrahedron: Asmmetry 1998, 9, 2377, (b) Kagan, H. B.; Riant, O Advances in Asmmetric Smthesis; Hassiner, A., Ed.: JAI Press Inc.: Greenwich, CT, 1997; vol. 2, p. 189. (c) Arrayas, R. G.: Adrio, T: Carretero, I C. Angew. Chent. Int. Ed. $2006,45,7674$.

10. Co, T. T.; Paek, S. H.: Shim, S. C.: Cho, C. S.; Kin, T.-T.; Choi, D. W: Kang, S. O., Teong, J. H. Organometallics 2003, 22, 1475 .

11. Paek, S. H.; Shim, S. C. Cho, C. S.; Kim, T.-T. Sinlett 2003, 6, 849

12. Co, T. T: Shim, S. C.: Cho, C. S.: Kin, D. U.: Kinn, T.-T. Bull. Korean Chem. Soc. 2005, 26, 1359.
13. Co, T. T.; Paek, S. H.: Shim, S. C.; Cho, C. S.: Kim, T.-T.; Organometallics 2005, 24, 4824

14. Co, T. T: Kim, T.-J Chent. Commun. 2006, 3537.

15. Hoang, Vo D. M.: Reddy, P. A. N.: Kim, T.-I. Tetrahedron Lett. $2007,48,8014$

16. (a) Boubekelu, L.; Ricard, L; Mezailles, N.: Floch, P. L. Organometallics 2005, 2t, 1065 . (b) Boubekeur, L.: Ricard, L ; Mezailles, N.; Demange, M.; Auffrant, A.; Floch, P. L. Orgonometallics 2006, 25, 3091

17. (a) Kubo, K.; Nakazawa, H.; Inagaki, H.; Mivoshi, K. Organometalics 2002, 21, 1942. (b) Vicente, $\mathrm{J}$; Abad, J.-A.; Clemente, R.: Lopez-Serrano, J.: de Arellano, M. C. R.; Iones, P. G.; Bautista, D. Organometallics 2003, 22,4248. (c) Leeson, M. A.; Nicholson, B. K.: Olsen, M. R. J. Organomet. Chem. 1999, 579 , 243. (d) Avis, M. W: van der Boom, M. E.; Elsevier, C. T.; Smeets, W. T.; Spek, A. L. J. Organontet. Chent. 1997, 527, 263. (e) Avis, M. W.: Goosen, M.; Elsevier, C. T.: Veldman, N.; Kooijman, H.; Spek, A. L. horg. Chimt Acta 1997, 264, 43. (f) Boubekeur, L.; Ulmer, S.: Ricard, L.; Mezailles, N.: Floch, P. L. Organontetallics $2006,25,315$.

18. (a) Holmes, R. R. Chent Rev 1996, 96, 927. (b) Chuit, C.: Corriu, R. J. P.; Young. I. C. Chem. Rev. 1993, 93, 1371 (c) Haaland, A. Angew: Chem. Int. Ed. Engl. 1989, 28, 992. 